\title{
Initial experience with a robotic hepatectomy program at a high-volume laparoscopic center: single-center experience and surgical tips
}

\author{
Boram Lee $^{1 \wedge}$, YoungRok Choi $^{2} \wedge$, Jai Young Cho ${ }^{1 \wedge}$, Yoo-Seok Yoon ${ }^{1 \wedge}$, Ho-Seong Han ${ }^{1 \wedge}$ \\ ${ }^{1}$ Department of Surgery, Seoul National University Bundang Hospital, Seoul National University College of Medicine, Seoul, Korea; ${ }^{2}$ Department \\ of Surgery, Seoul National University Hospital, Seoul National University College of Medicine, Seoul, Korea \\ Contributions: (I) Conception and design: All authors; (II) Administrative support: All authors; (III) Provision of study materials or patients: All \\ authors; (IV) Collection and assembly of data: B Lee, Y Choi; (V) Data analysis and interpretation: B Lee, Y Choi; (VI) Manuscript writing: All \\ authors; (VII) Final approval of manuscript: All authors. \\ Correspondence to: YoungRok Choi. Department of Surgery, Seoul National University Hospital, 100 and 101 Daehak-ro, Jongno-gu, Seoul 03080, \\ Korea. Email: choiyoungrok@gmail.com.
}

\begin{abstract}
Background: Despite the development of laparoscopic surgery, there are still inherent limitations associated with conventional laparoscopic instruments such as restrictions in movement and an inability for articulation. Robotic surgery may help to overcome the limitations of conventional laparoscopic surgery. The aim of this study was to present our initial experience with robotic hepatectomy $(\mathrm{RH})$ and discuss the steps required to develop an $\mathrm{RH}$ program at a high-volume laparoscopic hepatectomy $(\mathrm{LH})$ center.

Methods: We retrospectively reviewed prospectively collected data for 14 consecutive patients who underwent RH between 2017 and 2018. Clinicopathological characteristics and perioperative outcomes were compared with those reported in previous studies. The operation time of each procedure was analyzed to assess RH proficiency based on experience.

Results: Of the 14 patients, 12 patients (85.7\%) underwent robotic major hepatectomy. Median patient age was 54.5 years, while median body mass index (BMI) was $25.2 \mathrm{~kg} / \mathrm{m}^{2}$. The median operation time was 360 (range: 145-544) min. The median estimated blood loss (EBL) was 300 (range: 50-1,400) mL. Conversion to open surgery was not required in any case. The median length of hospital stay was 5 (range: 4-14) days. Major complications occurred in 2 patients (14.2\%), although both recovered without sequelae. The time required for hilar dissection, docking, and parenchymal transection gradually decreased after the first two cases of RH.

Conclusions: From our initial experience, RH might be considered as a feasible procedure in the liver resection, even in major hepatectomy. In addition, surgeons with sufficient experience in LH could rapidly adapt for RH. However, we have to make a system for education and monitoring of this innovative surgery for the patients' safety.
\end{abstract}

Keywords: Robotic surgery; robotic hepatectomy (RH); laparoscopic hepatectomy (LH); liver; laparoscopy

Submitted Jan 14, 2021. Accepted for publication May 23, 2021.

doi: $10.21037 / \mathrm{atm}-21-202$

View this article at: https://dx.doi.org/10.21037/atm-21-202

\footnotetext{
^ ORCID: Boram Lee, 0000-0003-1567-1774; YoungRok Choi, 0000-0003-2408-7086; Jai Young Cho, 0000-0002-1376-956X; Yoo-Seok Yoon, 0000-0001-7621-8557; Ho-Seong Han, 0000-0001-9659-1260.
} 


\section{Introduction}

Since the laparoscopic hepatectomy $(\mathrm{LH})$ was introduced by Gagner et al. in 1992 (1), it has been widely used for treatment of benign or malignant disease of the liver. While laparoscopic minor hepatectomy and left lateral sectionectomy are regarded as standard procedures, laparoscopic major liver resection and posterosuperior segment resection remain challenging procedures (2-4). There are inherent limitations associated with conventional laparoscopic instruments, such as restrictions in movement and dexterity due to rigidity and an inability for articulation $(5,6)$. Robotic surgery may help to overcome the limitations of conventional laparoscopic surgery. Indeed, the robotic platform allows for the use of endowrist and articulated instruments that mimic the seven degrees of motion of the human hand $(6,7)$.

In 2003, Giulianotti et al. reported the first case of a robot-assisted laparoscopic segmental liver resection (8). Since then, liver surgeons have attempted to expand the application of robotic systems in hepatic resection. Several studies have reported that robotic hepatectomy $(\mathrm{RH})$ is both safe and feasible (9-14). Although operation times are longer for $\mathrm{RH}$ than for $\mathrm{LH}$, a recent meta-analysis demonstrated that the postoperative complications and oncologic outcomes of RH are comparable to those of LH (15). However, previous studies focused on the technical feasibility of RH by comparing results with $\mathrm{LH}$ or open hepatectomy $(\mathrm{OH})$. In contrast, few studies have focused on the introduction of $\mathrm{RH}$ or factors to consider when introducing $\mathrm{RH}$, which are critical for ensuring patient safety.

Since the LH program began at our center in 2003 , we have performed more than 1,200 LH procedures. The RH program was launched in 2017 (Figure 1). The current study aimed to (I) present our initial experience with $\mathrm{RH}$ and (II) discuss the steps necessary when establishing an RH program at a high-volume $\mathrm{LH}$ center.

We present the following article in accordance with the STROBE reporting checklist (available at https://dx.doi. org/10.21037/atm-21-202).

\section{Methods}

We retrospectively reviewed prospectively collected data from 14 consecutive patients who underwent $\mathrm{RH}$ using the da Vinci ${ }^{\circledR}$ Xi surgical system (Intuitive Surgical Inc., Sunnyvale, CA, USA) from November 2017 to
December 2018 at single center in Korea. All operations were performed by a single surgeon who had performed more than $200 \mathrm{LH}$ procedures. We collected and analyzed data related to patient age, sex, body mass index (BMI), pathological diagnosis, extent of liver resection, mass size $(\mathrm{cm})$, operation time (min), estimated blood loss (EBL, $\mathrm{mL})$, docking time (min), resection margin $(\mathrm{mm})$, and hospital stay (days). Early complications were defined as postoperative complications within 30 days after surgery, which were graded using the Clavien-Dindo classification system (16). We reviewed the duration of each procedure to assess proficiency according to experience in four patients who underwent robotic right hemihepatectomy (RRH). "Docking time" was defined as the time interval from port placements to docking of the robot. "Hilum dissection time" was defined as the time interval from the start of dissection to the end of dissection. "Parenchymal time" was defined as the total time required for parenchymal transection. In addition, we reviewed relevant studies published in the PubMed or Cochrane databases. Outcomes reported in the literature were then compared to those of $\mathrm{RH}$ at our center.

The present study was performed in accordance with the Declaration of Helsinki (as revised in 2013). The protocol of this retrospective cohort study was approved by the institutional review board of Seoul National University Hospital, Seoul, Korea, an academic hospital affiliated with Seoul National University, College of Medicine (Approval No. B-2009-147-1159). Informed consent was waived because of the retrospective nature of the study and the analysis used anonymous clinical data.

\section{Surgical procedure (Figure 2)}

\section{Patient selection}

Selection criteria for patients with RH were the same as those for LH patients with a history of upper abdominal surgery were included. All patients provided written informed consent for the new $\mathrm{RH}$ procedure.

\section{Patient position and port placement}

The patient was placed in the supine position with the operating table tilted slightly to the left side, and in a $15^{\circ}$ reverse Trendelenburg position. For right-sided RH, a $12-\mathrm{mm}$ port was placed at the umbilicus in an open manner, and an intra-abdominal pressure of $13 \mathrm{mmHg}$ was achieved. Typically, four trocars are used with the da $\operatorname{Vinci}^{\circledR} \mathrm{Xi}$ surgical system, as shown in Figure $2 \mathrm{~A}$. The figure also 


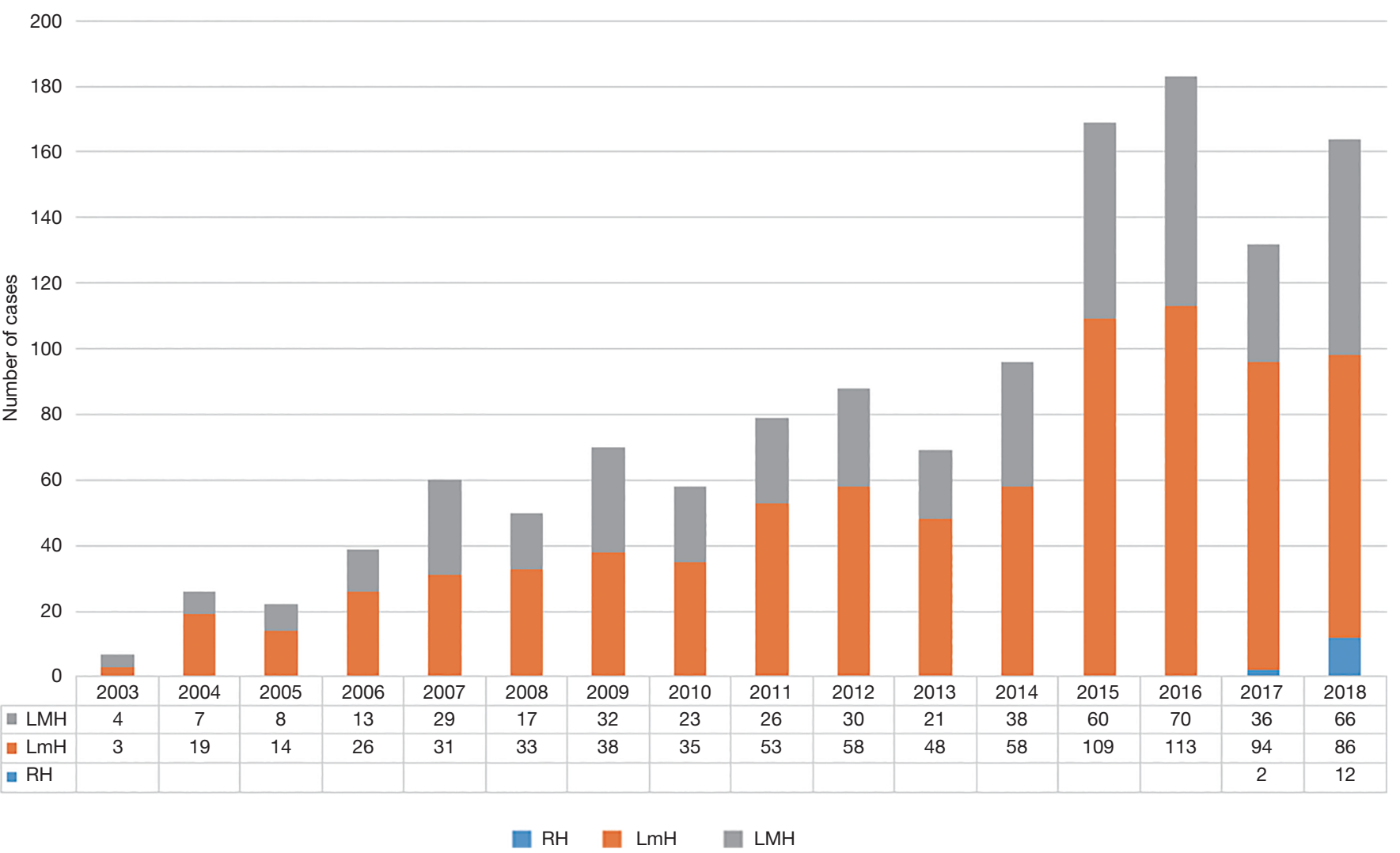

Figure 1 Experience of LH. LH, laparoscopic hepatectomy; RH, robotic hepatectomy; LmH, laparoscopic minor hepatectomy; LMH, laparoscopic major hepatectomy.

shows the 2-mm incision through which a long tube with a small diameter was inserted for Pringle's maneuver. Each port site was positioned at least $8 \mathrm{~cm}$ apart to prevent collision. In addition, ports were positioned 10 to $20 \mathrm{~cm}$ from the target anatomy.

\#Tip: the port's position should be based on the size of the abdomen and the location of the target lesion in the liver, considering the short length of the robot's harmonic scalpel when compared with those of the other instruments.

\#Tip: the port site should be placed approximately $15 \mathrm{~cm}$ away from the predicted center of the resection plane because the distance between the starting point of liver resection at the edge of the liver and the upper end of the anatomical resection line located in the deep part of the abdominal cavity is quite long.

\section{Surgical procedure}

The falciform ligament was dissected up to the inferior vena cava (IVC), following which the right hepatic vein (RHV) was exposed via careful dissection. Then, a tunnel was created between the RHV and middle hepatic vein (MHV) for the Hanging maneuver or for guiding anatomical resection. The liver was fully mobilized after resecting the coronary and triangular ligaments. The $4^{\text {th }}$ arm was used to lift or retract the right liver when the peritoneum was dissected at the inferior surface of the liver (Figure 2B). The right adrenal gland was carefully separated from the inferior surface of the liver (Figure 2C), in order to minimize the risk of bleeding during the perioperative period due to adrenal gland injury. The retractor or $4^{\text {th }}$ arm was used to lift the liver in the cephalic direction, while the short hepatic veins and IVC ligament were ligated. For the Hanging maneuver, a soft and elastic tube or plastic band was passed through the tunnel between the RHV and MHV, although this procedure was not considered essential. Retrograde cholecystectomy was performed after resecting the cystic artery and cystic duct in a classic manner. Both ends of the nylon tape were removed after encircling the hepatic pedicle, which can be used for the Pringle maneuver, through the long plastic tube inserted through the $2-\mathrm{mm}$ 

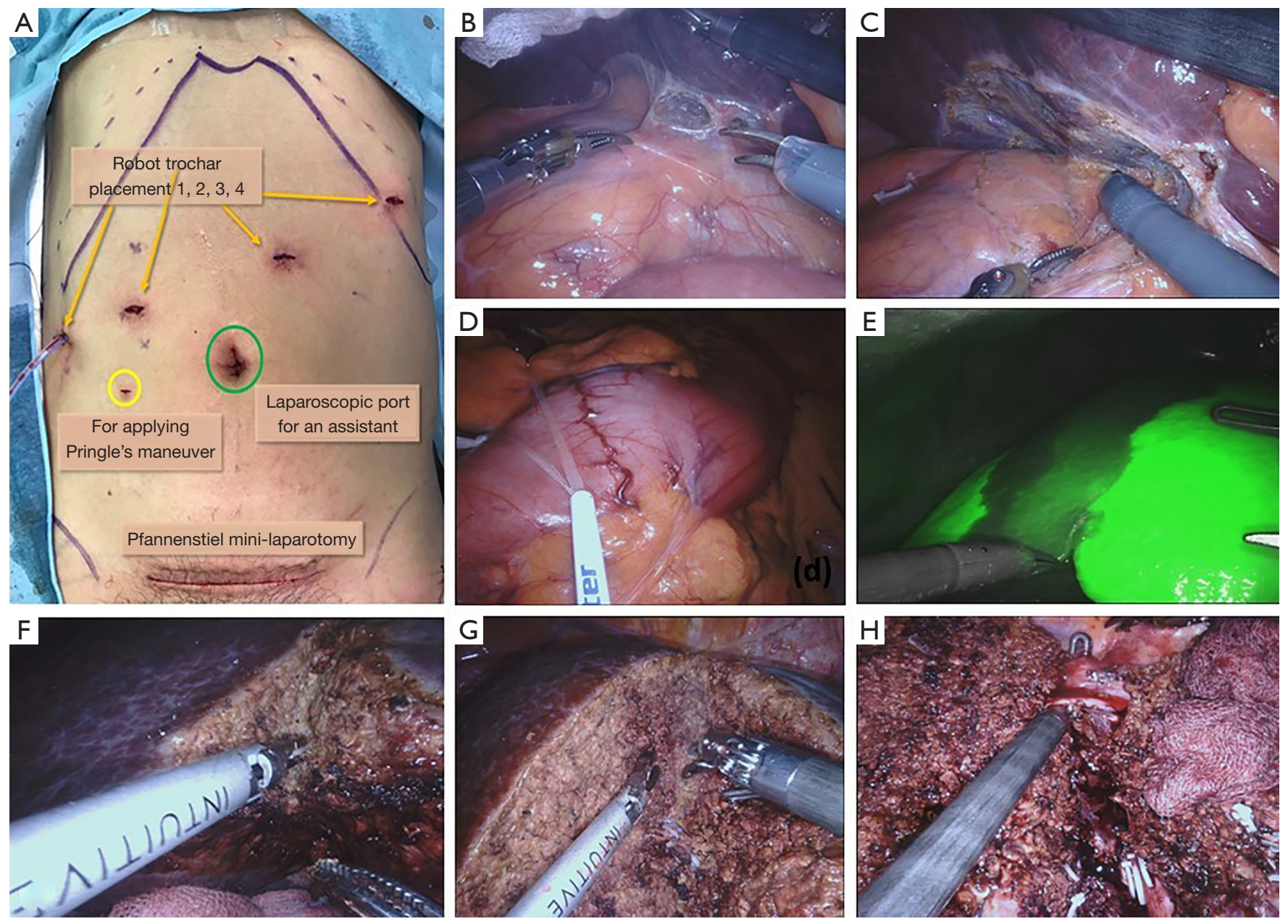

Figure 2 Procedure of RH. (A) Port placement with mini-laparotomy for extracting a specimen; (B) with lifting the right liver up, peritoneal reflexion is dissected; (C) right adrenal gland separation from the inferior surface of the liver; (D) preparation of Pringles maneuver using the plastic tube and a Nylon tape; (E) the resection line, along the boundary of the right liver, was marked using the method combined with ICG-fluorescence images and discoloration of the right liver; (F) superficial parenchymal dissection along the boundary of the ischemic area; (G) parenchymal dissection with using the combination of a bipolar forceps and a Harmonic scalpel; $(\mathrm{H}) \mathrm{RHV}$ is hanging on the instrument. RH, robotic hepatectomy; ICG, indocyanine green; RHV, right hepatic vein.

incision. The nylon tape was used to fasten the inflow of the hilum when pushing the tube to the hilum (Figure 2D). The right hepatic artery and right portal vein were dissected and transected. The resection line, which was located along the boundary of the right liver, was marked based on indocyanine green (ICG)-fluorescence images and discoloration of the right liver (Figure 2E).

\#Tip: leave a long round ligament stump or the gallbladder in the gallbladder bed of the liver for retraction, as this can help to create a good surgical field during hilum dissection.

\#Tip: it is not common for ICG uptake in the right posterior section, even after we divided the right hepatic artery and right portal vein. There are two possible explanations for this case. First, it would have shown because of the intrahepatic vascular shunt. Second, ICG might be uptake through the right inferior hepatic vein (RIHV) (about $12 \mathrm{~mm}$ ).

The superficial hepatic parenchyma was transected along the boundary of discoloration on the liver surface using an 
ultrasonic or electrocautery device (Figure $2 F$ ). The deep parenchyma was transected using a bipolar crushing method and an ultrasonic device equipped with an activation tip (Figure 2G). Further parenchymal dissection was used to expose and isolate the RHV, which was resected using an endoscopic stapler (Figure 2H).

\#Tip: avoid excessive retraction of the RHV in the lateral direction, which can cause narrowing of the IVC or tearing of the RHV after stapling.

\#Tip: as the branches of the MHV are vulnerable, complete isolation should be performed gently prior to resection of the branches.

\#Tip: Pringle's maneuver can be performed using nylon tape and a long tube when immediate reduction of inflow is necessary. In patients with cirrhosis, selective inflow occlusion techniques could apply to reduce blood loss and injury to the liver function.

\#Tip: when there is a high risk of bleeding, an assistant can perform Pringle's maneuver after encircling the hilum with tape without the need to change the robot arm, which can help to decrease bleeding and maintain a clear surgical field.

\#Tip: lateral traction of the liver can be achieved using one of several methods (e.g., rubber band traction, assistance, robot arm, etc.).

\section{Specimen extraction}

Specimens were extracted via Pfannenstiel mini-laparotomy and placed in a vinyl endoscopy bag. One closed suction drain was left in the subphrenic area, and a small drain was left within the fascia at the mini-laparotomy site.

\section{Statistics}

Statistical analysis was processed using the SPSS software package for Windows, version 22 (IBM Corporation, Armonk, NY, USA). The demographic and perioperative characteristics were summarized using descriptive analyses, and all qualitative values are presented as median and interquartile range (IQR) unless stated otherwise.

\section{Results}

\section{Patient demographics and clinical outcomes}

Median patient age was 54.5 (range: 29-69) years. Twelve of the 14 included patients were male. The median BMI was 25.2 (range: $20-30.8) \mathrm{kg} / \mathrm{m}^{2}$. Twelve patients $(85.7 \%$ ) underwent major $\mathrm{RH}$, including one case of additional hepaticojejunostomy. One patient underwent a left lateral sectionectomy through an umbilical single incision using the da Vinci ${ }^{\circledR} \mathrm{Xi}^{\mathrm{TM}}$ Single Site ${ }^{\mathrm{TM}}$ system (17). The median operation time for RH was 360 (range: 145-544) min. The median EBL was 300 (range: 50-1,400) mL. Conversion to open or laparoscopic surgery was not required in any case. The median duration of hospitalization was 5 (range: 4-14) days. The median resection margin was 10 (range: 1-45) mm. Patient characteristics and clinical outcomes are summarized in Table 1.

\section{Postoperative complications and short-term outcomes}

Table 2 summarizes the postoperative complications and short-term outcomes observed among the 14 included patients. Early complications occurred in 2 patients (14.2\%). These included Clavien-Dindo grade IIIa complications requiring percutaneous drainage after extended left hemihepatectomy/hepaticojejunostomy and left hemihepatectomy, although both patients were discharged without any sequelae. In-hospital and 30-day mortality rates were both $0 \%$. There were no late complications or 30-day readmissions. During a median follow-up of 25 months, three patients were diagnosed with recurrence after curative surgery.

\section{Operation time for each procedure during $R R H$}

To assess operator proficiency according to experience, we compared operation times for each RRH procedure (Figure 3). Four of 12 patients underwent RRH (case numbers 1, 2, 4, and 14). Total operation time dramatically decreased after the first two cases of RRH. In particular, the time required for hilar dissection, docking, and parenchymal transection time gradually decreased.

\section{Discussion}

The results of the present study indicate that $\mathrm{RH}$ performed by experienced laparoscopic surgeons is associated with stable operative outcomes. Although the number of cases was rather small, our findings demonstrate the technical feasibility of $\mathrm{RH}$, even in cases of major surgery. Furthermore, the docking procedure is relatively easy to learn, even among surgeons with little experience using a robotic platform. Moreover, our results indicated that 
Table 1 Summary of demographics and clinical outcomes

\begin{tabular}{|c|c|}
\hline Variables & $\mathrm{RH}(\mathrm{n}=14)$ \\
\hline Median age [range], (year) & 54.5 [26-69] \\
\hline Male:female & $12: 2$ \\
\hline Median BMI [range], $\left(\mathrm{kg} / \mathrm{m}^{2}\right)$ & $25.2[20-30.8]$ \\
\hline \multicolumn{2}{|l|}{ Diagnosis } \\
\hline $\mathrm{HCC}$ & 9 \\
\hline $\mathrm{CCC}$ & 2 \\
\hline Metastatic cancer & 1 \\
\hline IHD stone & 1 \\
\hline Biliary stricture & 1 \\
\hline \multicolumn{2}{|l|}{ Type of operation } \\
\hline $\mathrm{RHH}$ & 5 \\
\hline $\mathrm{LHH}$ & 1 \\
\hline RAS & 1 \\
\hline RPS & 4 \\
\hline Ext. LHH & 1 \\
\hline LLS & 1 \\
\hline Tumorectomy (segment 8) & 1 \\
\hline Median tumor size [range], (cm) & $4.1[1.6-11.4]$ \\
\hline Median operation time [range], (min) & 360 [145-544] \\
\hline Median EBL [range], (mL) & $300[50-1,400]$ \\
\hline Median hospital day [range], (day) & $5[4-14]$ \\
\hline Median resection margin [range], $(\mathrm{mm})$ & $10[1-45]$ \\
\hline
\end{tabular}

$\mathrm{RH}$, robotic hepatectomy; $\mathrm{BMI}$, body mass index; $\mathrm{HCC}$, hepatocellular carcinoma; CCC, cholangiocarcinoma; IHD, intrahepatic duct; $\mathrm{RHH}$, right hemihepatectomy; $\mathrm{LHH}$, left hemihepatectomy; RAS, right anterior sectionectomy; RPS, right posterior sectionectomy; Ext. LHH, extended left hemihepatectomy; LLS, left lateral sectionectomy; EBL, estimated blood loss.

rapid adaptation to the use of a robotic system is possible even for advanced procedures such as hilar dissection and parenchymal transection, when performed by an experienced laparoscopic surgeon.

Tsilimigras et al. systematically reviewed 31 comparative studies of major RH ( $n=115)$ (18). They reported a mean operation time of $403.4 \pm 107.5 \mathrm{~min}$, EBL of $543.4 \pm 371 \mathrm{~mL}$, conversion rate of $8.6 \%$, hospital stay of $10.5 \pm 4.8 \mathrm{~d}$, and complication rate of $17 \%$ (18). Operative outcomes for RH were similar in our study (Table 3). In addition, there was no conversion to laparoscopy or open surgery in our study.

In Korea, Han et al. introduced LH for use in selected patients in 2002 (19). Since then, many center have reported safety and efficacy outcomes for various types of $\mathrm{LH}$, including major LH (20-30). Based on this accumulated experience, our center launched the RH program in 2017. In the beginning, there were several issues due to the use of a rigid camera system, unfamiliar surgical instruments, the time required to switch robotic arms, and the application of the suction and irrigation instruments for the timing of bleeding by an assistant. However, in the present study, rapid adaption to $\mathrm{RH}$ was achieved using a magnified $3 \mathrm{D}$ viewing system, arms capable of ergonomic movement, and an experienced assistant.

Results related to the influence of laparoscopic experience on robotic surgery outcomes remain controversial. Yoo et al. reported that outcomes achieved using three virtual endowrist modules were not significantly affected by the operator's laparoscopic experience (31). Abaza et al. concluded that experienced open surgeons could successfully apply open surgical skills to the robotic surgery system without laparoscopic experience (32). Although it may be possible to rapidly adapt to robotic surgery without laparoscopic experience in uncomplicated cases, laparoscopic experience is considered critical for complicated surgeries involving resection of the stomach, colon, or liver. Park et al. demonstrated that the surgeon's experience with laparoscopic gastrectomy decreases operation time after stabilization (33). Based on our findings and clinical experience, we believe that laparoscopic experience affects adaptation to RH.

The robotic platform shifts the primary surgeon away from the patient to the console, mandating the use of an assistant. The patient-side assistant must be skilled in the technical work associated with the robotic patient-side cart and be able to provide pure laparoscopic assistance occasionally (34). The assistant's role is to accomplish retraction, suction, and stapling in restricted areas and manage a limited number of ports. Given that the surgeons participating in $\mathrm{RH}$ as patient-side assistants had extensive experience in laparoscopic surgery, this may have helped to achieve rapid adaptation to RH. This suggests that the laparoscopic experience of both the surgical team and operator plays a key role in adaptation to RH.

Several studies have reported that robotic surgery can reduce the learning curve for complex minimally invasive 
Table 2 Postoperative complications and short-term outcomes

\begin{tabular}{|c|c|c|c|c|c|c|c|c|c|}
\hline Case & $\begin{array}{l}\text { Age } \\
\text { (year) }\end{array}$ & Sex & Diagnosis & $\begin{array}{l}\text { Type of } \\
\text { resection }\end{array}$ & $\begin{array}{l}\text { Early } \\
\text { complication }\end{array}$ & $\begin{array}{l}\text { Late } \\
\text { complication }\end{array}$ & $\begin{array}{l}\text { Recurrence } \\
\text { (months) }\end{array}$ & $\begin{array}{l}\text { Recurrence } \\
\text { site }\end{array}$ & $\begin{array}{l}\text { Follow-up } \\
\text { (months) }\end{array}$ \\
\hline 1 & 69 & M & $\mathrm{HCC}$ & $\mathrm{RHH}$ & 0 & 0 & No & & 27 \\
\hline 2 & 51 & M & $\mathrm{HCC}$ & $\mathrm{RHH}$ & 0 & 0 & No & & 9 \\
\hline 3 & 56 & M & $\mathrm{HCC}$ & RPS & 0 & 0 & No & & 25 \\
\hline 4 & 61 & M & $\mathrm{HCC}$ & $\mathrm{RHH}$ & 0 & 0 & No & & 26 \\
\hline 5 & 52 & M & $\mathrm{HCC}$ & RAS & 0 & 0 & Yes [4] & Liver & 18 \\
\hline 6 & 59 & M & $\mathrm{HCC}$ & RPS & 0 & 0 & No & & 25 \\
\hline 7 & 43 & M & $\mathrm{HCC}$ & RPS & 0 & 0 & No & & 26 \\
\hline 8 & 59 & $\mathrm{~F}$ & $\mathrm{ccc}$ & $\begin{array}{l}\text { Ext. LHH and } \\
\text { HJ-stomy }\end{array}$ & $\begin{array}{l}\text { Illa, HJ leak, PTBD } \\
\text { insertion }\end{array}$ & 0 & Yes [1] & Liver, LN & 16 \\
\hline 9 & 43 & M & $\mathrm{HCC}$ & RPS & 0 & 0 & No & & 21 \\
\hline 10 & 56 & $M$ & $\mathrm{ccc}$ & LHH & $\begin{array}{l}\text { Illa, resection margin fluid } \\
\text { collection PCD insertion }\end{array}$ & 0 & Yes [16] & Kidney, LN & 21 \\
\hline 11 & 53 & M & $\mathrm{HCC}$ & S8 tumorectomy & 0 & 0 & No & & 37 \\
\hline 12 & 48 & $\mathrm{~F}$ & Metastasis & Single site LLS & 0 & 0 & No & & 26 \\
\hline 13 & 29 & M & IHD stone & RPS & 0 & 0 & - & & 1 \\
\hline 14 & 64 & $M$ & $\begin{array}{l}\text { Biliary } \\
\text { stricture }\end{array}$ & $\mathrm{RHH}$ & 0 & 0 & - & & 19 \\
\hline
\end{tabular}

HCC, hepatocellular carcinoma; CCC, cholangiocarcinoma; IHD, intrahepatic duct; RHH, right hemihepatectomy; RPS, right posterior sectionectomy; RAS, right anterior sectionectomy; Ext. LHH, extended left hemihepatectomy; HJ-stomy, hepaticojejunostomy; LHH, left hemihepatectomy; S8, segment 8; LLS, left lateral sectionectomy; HJ, hepaticojejunostomy; PTBD, percutaneous biliary drainage; PCD, percutaneous drainage; LN, lymph node.

procedures due to its many advantages over laparoscopic and open surgeries (35-37). The learning curve for laparoscopic major hepatectomy has been described based on 96 cases from Koffron et al., 62 cases from Buell et al., and 173 cases from Nomi et al. (38-40). Another previous study indicated that 73 cases were required to overcome the learning curve for laparoscopic major hepatectomy $(41,42)$. Chen et al. demonstrated that the learning curve for major RH required an initial phase of only 15 cases and an intermediate phase of 25 cases (43). In the present study, favorable outcomes were obtained despite the relatively small number of cases. Taken together, these findings suggest that the learning curve for $\mathrm{RH}$ is relatively shorter than that for LH. Although $\mathrm{RH}$ and $\mathrm{LH}$ are similar in terms of operative procedures, $\mathrm{RH}$ has advantages with respect to articulation and tremor correction, indicating that experience with LH may aid in adaptation to RH.

Despite the advantages of robotic surgery, there are some limitations to RH. First, devices for parenchymal dissection during RH such as the Cavitron Ultrasonic Surgical Aspirator (CUSA, Valleylab, Offaly, Ireland) or LigaSure (Medtronic, Minneapolis, MN, USA) are significantly limited. When performing RH, we used endowristed bipolar forceps and harmonic scalpel ultrasonic shears for parenchymal dissection. However, the risk of bleeding is greater when using these instruments than when using a CUSA. Second, the da Vinci system utilizes a rigid 3D telescope. This limits the approach to the superior and posterior portions of the liver, in contrast to the flexible $3 \mathrm{D}$ imaging system used in laparoscopic surgery, which is useful for operating in a limited space, especially during liver mobilization and deep parenchymal transection (44). Despite these limitations, from our initial experience, $\mathrm{RH}$ might be considered as a feasible procedure in the liver resection, even in major hepatectomy. In addition, surgeons with sufficient experience in LH could rapidly adapt for 


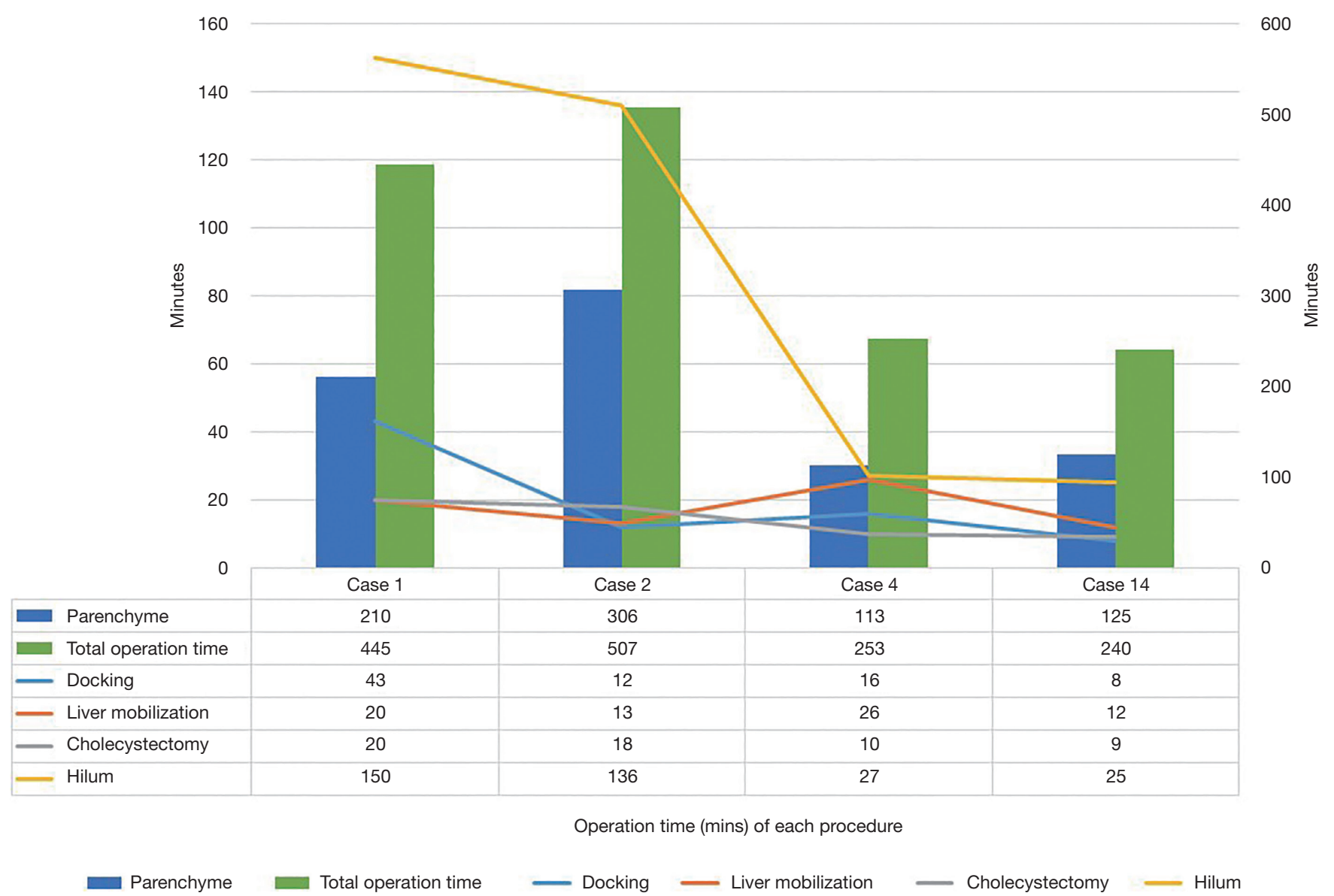

Figure 3 The procedure time according to experience in RRH. RRH, robotic right hemihepatectomy.

Table 3 Perioperative demographics and clinical outcomes of robotic major hepatectomy

\begin{tabular}{|c|c|c|c|c|c|c|c|}
\hline Authors & Year & $\begin{array}{c}\text { No. } \\
\text { patients }\end{array}$ & $\begin{array}{l}\text { Major hepatectomy/ } \\
\text { minor hepatectomy }\end{array}$ & $\begin{array}{l}\text { Operaion time, min } \\
\text { [range and/or SD] }\end{array}$ & $\begin{array}{c}\mathrm{EBL}, \mathrm{mL} \\
\text { [range and/or SD] }\end{array}$ & $\begin{array}{l}\text { Hospital stay, day } \\
\text { [range and/or SD] }\end{array}$ & $\begin{array}{c}\text { Early complication } \\
\text { rate }(\%)\end{array}$ \\
\hline This study & 2020 & 14 & $12 / 2$ & 375 [145-544] & $300[50-1,400]$ & $5[4-14]$ & 14.3 \\
\hline Ji et al. & 2011 & 13 & $9 / 4$ & 338 & 280 & 6.7 & 7.8 \\
\hline Choi et al. & 2012 & 30 & $20 / 30$ & 507 [120-812] & $343[95-1,500]$ & $11.7[5-46]$ & 20 \\
\hline Chen et al. & 2017 & 183 & $92 / 91$ & 434 [142-805] & $195[50-2,000]$ & $13.6[5-41]$ in phase I & 4.4 \\
\hline
\end{tabular}

EBL, estimated blood loss. 
RH. However, we have to make a system for education and monitoring of this innovative surgery for the patients' safety.

\section{Acknowledgments}

Funding: None.

\section{Footnote}

Reporting Checklist: The authors have completed the STROBE reporting checklist. Available at https://dx.doi. org/10.21037/atm-21-202

Data Sharing Statement: Available at https://dx.doi. org/10.21037/atm-21-202

Peer Review File: Available at https://dx.doi.org/10.21037/ atm-21-202

Conflicts of Interest: All authors have completed the ICMJE uniform disclosure form (available at https://dx.doi. org/10.21037/atm-21-202). The authors have no conflicts of interest to declare.

Ethical Statement: The authors are accountable for all aspects of the work in ensuring that questions related to the accuracy or integrity of any part of the work are appropriately investigated and resolved. The present study was performed in accordance with the Declaration of Helsinki (as revised in 2013). The protocol of this retrospective cohort study was approved by the institutional review board of Seoul National University Hospital, Seoul, Korea, an academic hospital affiliated with Seoul National University, College of Medicine (Approval No. B-2009147-1159). Informed consent was waived because of the retrospective nature of the study and the analysis used anonymous clinical data.

Open Access Statement: This is an Open Access article distributed in accordance with the Creative Commons Attribution-NonCommercial-NoDerivs 4.0 International License (CC BY-NC-ND 4.0), which permits the noncommercial replication and distribution of the article with the strict proviso that no changes or edits are made and the original work is properly cited (including links to both the formal publication through the relevant DOI and the license). See: https://creativecommons.org/licenses/by-nc-nd/4.0/.

\section{References}

1. Gagner M, Rheault M, Duluc J. Laparoscopic partial hepatectomy for liver tumour. Surg Endosc 1992;6:99.

2. Buell JF, Cherqui D, Geller DA, et al. The international position on laparoscopic liver surgery: The Louisville Statement, 2008. Ann Surg 2009;250:825-30.

3. Cho JY, Han HS, Yoon YS, et al. Feasibility of laparoscopic liver resection for tumors located in the posterosuperior segments of the liver, with a special reference to overcoming current limitations on tumor location. Surgery 2008;144:32-8.

4. Yoon YS, Han HS, Cho JY, et al. Total laparoscopic liver resection for hepatocellular carcinoma located in all segments of the liver. Surg Endosc 2010;24:1630-7.

5. Wilson EB. The evolution of robotic general surgery. Scand J Surg 2009;98:125-9.

6. Lanfranco AR, Castellanos AE, Desai JP, et al. Robotic surgery: a current perspective. Ann Surg 2004;239:14-21.

7. Desai PH, Lin JF, Slomovitz BM. Milestones to optimal adoption of robotic technology in gynecology. Obstet Gynecol 2014;123:13-20.

8. Giulianotti PC, Coratti A, Angelini M, et al. Robotics in general surgery: personal experience in a large community hospital. Arch Surg 2003;138:777-84.

9. Ziogas IA, Tohme S, Geller DA. Robotic vs. laparoscopic major hepatectomy. Mini-invasive Surg 2020;4:69.

10. Guan R, Chen Y, Yang K, et al. Clinical efficacy of robotassisted versus laparoscopic liver resection: a meta analysis. Asian J Surg 2019;42:19-31.

11. Wakabayashi G, Cherqui D, Geller DA, et al. Recommendations for laparoscopic liver resection: A report from the second international consensus conference held in Morioka. Ann Surg 2015;261:619-29.

12. Salloum C, Lahat E, Lim C, et al. Minimally invasive left lateral sectionectomy robot vs laparoscopy. HPB 2016;18:e234.

13. Choi GH, Choi SH, Kim SH, et al. Robotic liver resection: technique and results of 30 consecutive procedures. Surg Endosc 2012;26:2247-58.

14. Giulianotti PC, Sbrana F, Coratti A, et al. Totally robotic right hepatectomy: Surgical technique and outcomes. Arch Surg 2011;146:844-50.

15. Montalti R, Berardi G, Patriti A, et al. Outcomes of robotic vs laparoscopic hepatectomy: a systematic review and meta-analysis. World J Gastroenterol 2015;21:8441-51.

16. Clavien PA, Barkun J, de Oliveira ML, et al. The ClavienDindo classification of surgical complications: five-year experience. Ann Surg 2009;250:187-96. 
17. Kim W, Choi Y, Cho JY, et al. Robot single incision left lateral sectionectomy via da Vinci ${ }^{\circledR} \mathrm{Xi}^{\mathrm{TM}}$ Single Site $^{\mathrm{TM}}$ \# vaginal extraction of the specimen. Surg Oncol 2020;33:254-5.

18. Tsilimigras DI, Moris D, Vagios S, et al. Safety and oncologic outcomes of robotic liver resections: a systematic review. J Surg Oncol 2018;117:1517-30.

19. Han HS, Min SK, Kim YW, et al. Laparoscopy-assited major liver resection. J Korean Soc Endosc Laparosc Surg 2002;5:75-9.

20. Han HS, Cho JY, Yoon YS, et al. Total laparoscopic living donor right hepatectomy. Surg Endosc 2015;29:184.

21. Han HS, Cho JY, Yoon YS. Techniques for performing laparoscopic liver resection in various hepatic locations. J Hepatobiliary Pancreat Surg 2009;16:427-32.

22. Cho JY, Han HS, Yoon YS, et al. Experiences of laparoscopic liver resection including lesions in the posterosuperior segments of the liver. Surg Endosc 2008;22:2344-9.

23. Guro H, Cho JY, Han HS, et al. Laparoscopic liver resection of hepatocellular carcinoma located in segments 7 or 8. Surg Endosc 2018;32:872-8.

24. Choi H, Han HS, Yoon YS, et al. Laparoscopic anatomic segment 6 liver resection using the glissonian approach. Surg Laparosc Endosc Percutan Tech 2017;27:e22-5.

25. Jang JY, Han HS, Yoon YS, et al. Three-dimensional laparoscopic anatomical segment 8 liver resection with glissonian approach. Ann Surg Oncol 2017;24:1606-9.

26. Ho KM, Han HS, Yoon YS, et al. Laparoscopic anatomical segment 2 segmentectomy by the glissonian approach. J Laparoendosc Adv Surg Tech A 2017;27:818-22.

27. Ho KM, Han HS, Yoon YS, et al. Laparoscopic total caudate lobectomy for hepatocellular carcinoma. J Laparoendosc Adv Surg Tech A 2017;27:1074-8.

28. Stoot JH, van Dam RM, Coelen RJ, et al. The introduction of a laparoscopic liver surgery programme: a cost analysis of initial experience in a university hospital. Scand J Surg 2012;101:32-7.

29. Goh BKP, Chan CY, Lee SY, et al. Early experience with totally laparoscopic major hepatectomies: single institution experience with 31 consecutive cases. ANZ J Surg 2018;88:E329-33.

30. Jang EJ, Kim KW. Early experience of laparoscopic liver resection: a single institution experience with 37 consecutive cases. Ann Hepatobiliary Pancreat Surg 2019;23:115-21.

31. Yoo BE, Kim J, Cho JS, et al. Impact of laparoscopic experience on virtual robotic simulator dexterity. J Minim Access Surg. 2015;11:68-71.
32. Abaza R. The robotic surgery era and the role of laparoscopy training. Ther Adv Urol 2009;1:161-5.

33. Park SS, Kim MC, Park MS, et al. Rapid adaptation of robotic gastrectomy for gastric cancer by experienced laparoscopic surgeons. Surg Endosc 2012;26:60-7.

34. Nayyar R, Yadav S, Singh P, et al. Impact of assistant surgeon on outcomes in robotic surgery. Indian J Urol 2016;32:204-9.

35. Allaf M, Patriciu A, Mazilu D, et al. Overview and fundamentals of urologic robot-integrated systems. Urol Clin North Am 2004;31:671-82, vii.

36. Joseph JV, Vicente I, Madeb R, et al. Robot assisted vs pure laparoscopic radical prostatectomy: are there any differences? BJU Int 2005;96:39-42.

37. Bonaros N, Schachner T, Oehlinger A, et al. Robotically assisted totally endoscopic atrial septal defect repair: insights from operative times, learning curves, and clinical outcome. Ann Thorac Surg 2006;82:687-93.

38. Koffron AJ, Auffenberg G, Kung R, et al. Evaluation of 300 minimally invasive liver resections at a single institution: less is more. Ann Surg 2007;246:385-92.

39. Buell JF, Thomas MT, Rudich S, et al. Experience with more than 500 minimally invasive hepatic procedures. Ann Surg 2008;248:475-86.

40. Nomi T, Fuks D, Kawaguchi Y, et al. Learning curve for laparoscopic major hepatectomy. Br J Surg 2015;102:796-804.

41. Lee B, Choi Y, Lee W, et al. Timing for introduction of total laparoscopic living donor right hepatectomy; initial experience based on the data of laparoscopic major hepatectomy. Transplantation 2021;105:1273-9.

42. Hasegawa Y, Nitta H, Takahara T, et al. Safely extending the indications of laparoscopic liver resection: when should we start laparoscopic major hepatectomy? Surg Endosc 2017;31:309-16.

43. Chen PD, Wu CY, Hu RH, et al. Robotic major hepatectomy: Is there a learning curve? Surgery 2017;161:642-9.

44. Hong SK, Shin E, Lee KW, et al. Pure laparoscopic donor right hepatectomy: perspectives in manipulating a flexible scope. Surg Endosc 2019;33:1667-73.

Cite this article as: Lee B, Choi Y, Cho JY, Yoon YS, Han HS Initial experience with a robotic hepatectomy program at a high-volume laparoscopic center: single-center experience and surgical tips. Ann Transl Med 2021;9(14):1132. doi: 10.21037/atm21-202 